\title{
DE LUANDA PARA LISBOA: O RETORNO, DE DULCE MARIA CARDOSO, E OS RESTOS DO IMPÉRIO
}

\author{
FROM LUANDA TO LISBOA: O RETORNO, \\ DE DULCE MARIA CARDOSO, \\ AND THE REST OF EMPIRE
}

Luca Fazzini ${ }^{1}$

\section{RESUMO}

De acordo com quanto analisado por Jacinto do Prado Coelho em Originalidade da literatura portuguesa, o imaginário coletivo lusitano apoiou-se, ao longo dos séculos, numa série de referências provenientes da literatura. A própria historiografia portuguesa, durante muito tempo, constituiu-se tendo como fonte primária a literatura: mitos, memórias, crónicas e relatos de viagem participaram tanto da construção da história oficial pelo poder, quanto daquela que pode ser definida a poética da Nação portuguesa - durante década ao serviço da ideologia imperial propagandeada pelo Estado Novo. No entanto, a partir do ano de 1974, com o fim da ditadura salazarista e da chamada Guerra Colonial, a literatura passou a encenar o momento da perda, o epílogo da longa tradição ultramarina. Passou a interrogar os fantasmas e as fantasias imperiais $\nabla$ retomando a expressão de A. P. Ferreira e M. C. Ribeiro. Tendo, portanto, como ponto de partida a estrita ligação, em Portugal entre literatura, historiografia e imaginário coletivo, com o presente artigo pretendo oferecer uma análise crítica do romance O retorno (2011), de Dulce Maria Cardoso, que vise indagar, questionar os restos do império.

PALAVRAS-CHAVE: Guerra Colonial; Imaginário Coletivo; História e Literatura 


\section{ABSTRACT}

According to the analysis of Jacinto do Prado Coelho in Originalidade da literatura portuguesa, the portuguese collective consciousness has been built over time through a series of references from the literature. For a long time, portoguese historiography has used literature as its primary source: myths, memories and travel chronicles have contributed both to the construction of official history by the authorities and to what can be defined as the poetics of the nation - during the long time at the service of the Estado Novo and its propaganda of the imperial ideology. However, from 1974, in conjunction with the end of the salazarist dictatorship and the colonial war, the literature begins to narrate the moment of loss and the end of the long-lasting portuguese colonial tradition. Borrowing the expression of A.P. Ferreira and M.C. Ribeiro, the literature started to interrogate the spectres and fantasies of the empire. Therefore, building on the strong connection between portuguese literature, historiography and collective consciousness, this article presents a critical analysis of the novel $O$ retorno by Dulce Maria Cardoso, which seeks to investigate and analyse the remains of the empire.

KEYWORDS: Colonial War; Collective Imaginary; History and Literature

\section{LITERATURA, HISTORIOGRAFIA E IDENTIDADE NACIONAL}

A literatura portuguesa contemporânea, produzida a partir daquela viragem radical na história de Portugal que foi o 25 de abril 1974, procurando inovações tanto no plano formal quanto no do conteúdo, manifestou a necessidade de pôr em discussão e de repensar as coordenadas da identidade nacional.

Uma etapa fulcral neste caminho foi o lento trabalho de desconstrução do imaginário imperial propagandeado pelo fascismo. De facto, o ponto final à secular aventura colonial em África obrigou o português, que sempre se viu e se representou numa perspetiva expansionista e marítima, a pensar-se a si próprio partindo do espaço-nação ibérico e europeu. De facto, o ano de 1974 marcou o princípio de uma época nova, caraterizada pela democracia (1974), pela adesão à CEE (1986) e à chamada Zona Euro (1999), pela entrega de Macau (1999). Uma época que pode ser considerada menos "atlântica" e mais "europeia”, pois significou a conclusão da longa tradição marítima lusitana, o não ser mais Lisboa o centro de um vasto império do Minho a Timor, mas apenas a margem de um continente ao qual Portugal tinha virado as costas já a partir do século XV.

Jacinto do Prado Coelho, ao enfatizar a presença do mar e da vocação expansionista como sendo elementos imprescindíveis para pensar Portugal, a literatura portuguesa e a vida histórica do país, refere a célebre expressão de Latino Coelho segundo a qual "Portugal é nação desde o dia 
em que saiu a cruzar os mares" (COELHO, 1992, p. 25) e conclui: "eis, na verdade, uma das ideias-motrizes mais tenazes na cultura portuguesa: o eixo da vida histórica portuguesa está no binómio Continente-Ultramar, Portugal não encontraria justificação em si próprio, mas num movimento centrífugo, de «reacção»". (COELHO, 1992, p. 26)

Por conseguinte, a independência das ex-colónias africanas salientou a urgência de uma reflexão identitária que tenha em conta o caráter europeu do pequeno retângulo ibérico, tradicionalmente ocultado em favor de "glórias" ultramarinas. Deste processo resulta uma maior abertura, não apenas política, mas sobretudo cultural, à Europa, que no entretanto se tornou um interlocutor necessário. Em O imaginário português neste fim de século, Eduardo Lourenço sublinha a abertura artística que Portugal viveu nas últimas décadas. Escreve o filósofo:

E para o caso menos interessa a celebridade desses diversos artistas que o facto de com eles e através deles o conceito mesmo de imaginário cultural ter adquirido não só outra amplitude como outro sentido. Outro estatuto, digamos. Em suma, deixámos, pelo menos em parte, de nos viver como encerrados em nós mesmos e vemo-nos agora, por assim dizer, no meio dos outros. (LOURENÇO, 1999, p.20)

De facto, considerar a chamada Portugalidade a partir do espaço ultramarino significou, para o português, não ter interlocutor nenhum, enquanto os outros com os quais compartilhava a realidade imperial eram os colonizados, subalternos sem voz e sem a possibilidade de agir como sujeitos na construção desse imaginário.

Para Eduardo Lourenço, uma análise dos mais recentes trabalhos artísticos - não apenas literários, mas que envolvam também a pintura e a escultura, assim como o cinema e o teatro, entre outros - manifestaria uma sempre maior visibilidade da produção portuguesa no exterior, na Europa, e uma profunda abertura para ela. Tais obras, de perspetivas mais internacionais, mostrariam a grande mudança que, a partir da década de oitenta do século XX, tem vindo a ocupar a arte. Tratar-se-ia, segundo Lourenço, de uma rutura com os modelos do modernismo, personificado na figura de Fernando Pessoa:

Neste momento, em relação com as necessidades específicas do nosso imaginário neste fim de século, o barco de Pessoa - o do modernismo - está parado. Mesmo na imaginação. Ele mesmo navega algures, nos oceanos de sonhos que substituiu aos nossos velhos mares demasiado navegados e revisitados. Nós - quer dizer, a cultura portuguesa - devemos continuar a nossa viagem no tempo presente sem ele. Alguns dizem mesmo contra ele. [...] Não nos ocupamos mais de Pessoa. Deixemo-lo na sua pátria de sonho, para defrontar sem ele a vida que não sonha. A do nosso presente que a sonha de outra maneira. (LOURENÇO, 1999, p. 20) 
Nas palavras de Eduardo Lourenço, perceber-se-ia a necessidade artística de quebrar a tradição modernista, demasiado cheia de mitologias messiânicas e de oníricas loucuras imperiais, para se renovar e para se confrontar com as tensões e as dinâmicas provenientes da Europa. Tal movimento de renovação dos elementos canónicos da tradição, para lhe dar diferentes sentidos, conjugou-se, no caso português, com a necessidade de desconstruir o imaginário coletivo, assim como foi escrupulosamente propagandeado pelo fascismo, durante os anos do Estado Novo.

Em "Desconstrução da memória imperial: literatura, arte e historiografia”, ensaio publicado no volume organizado por Margarida Calafate Ribeiro, Fantasmas e fantasias imperiais no imaginário português contemporâneo, Francisco Bethencourt oferece uma ampla panorâmica de como tanto a literatura, quanto a arte portuguesa contemporânea têm trabalhado para desconstruir o imaginário imperial - movimento revolucionário, na medida em que nele residia uma crítica radical à comunidade imaginária ${ }^{2}$ erigida pelo nacionalismo Salazarista.

Nesse âmbito, Bethencourt destaca duas obras em particular, ambas marcadas por um mesmo movimento de rutura: a escultura de D. Sebastião, esculpida por João Cutileiro e inaugurada em Lagos em 1972, quando Portugal vivia ainda o jugo do fascismo, e o romance As naus, de António Lobo Antunes, publicado em 1988.

A estátua de Cutileiro, das dimensões de $200 / 90 / 80$ cm, realizada em mármore policromado, travertino e calçada portuguesa, hoje na Praça Gil Eanes, em Lagos, apresenta-se como inacabada, robusta, íngreme em clara divergência com as lógicas que sustentavam a estatuária modernista. Um antimonumento, a representar uma das figuras mais icónicas do passado lusitano. Ao fazer uma comparação entre o mencionado romance de Lobo Antunes, e a escultura de Cutileiro, Bethencourt afirma que "a aplicação de uma forma de representação anacrónica a uma figura histórica constitui um golpe de génio face ao panorama estagnado da estatuária nacional, numa escolha que precede dezasseis anos [...] o anacronismo assumido a nível literário por Lobo Antunes” (BETHENCOURT, 2003, p. 73).

Todavia, se no âmbito literário e artístico seria possível encontrar a necessidade de uma inovação profunda, por outro lado, a historiografia portuguesa não compartilhou as mesmas tensões e inquietações, pois, segundo Bethencourt, continuaria a ser fortemente condicionada pelo peso da história do império, mais do que pela história do reino de Portugal no seu espaço europeu - numa relação de disparidade dificilmente comparável com os outros contextos marcados pela forte presença da experiência colonial. A vocação expansionista e ultramarina, de facto, domina a historiografia portuguesa, já a partir da segunda metade do século XV, até chegar ao século XX, não obstante apresente, em alguns casos, diversidades devidas à emergência e à consolidação de diferentes metodologias e pressupostos teóricos. Neste âmbito, Bethencourt destaca o caso particular da 
História de Portugal, dirigida por José Mattoso e publicada em 1993-1994. Esta obra, sui generis se considerada no interior do corpus historiográfico português, seria deliberadamente restrita ao território europeu e a sua base ideológica residiria no contexto e nas dinâmicas políticas que envolveram a Europa na década de noventa do século XX.

Portanto, aquilo que seria possível concluir depois de uma atenta análise diacrónica da historiografia portuguesa seria a sua constante orientação e envolvimento ideológico. A matéria histórica, em Portugal, foi de facto sempre orientada pelas visões de "todos os que até hoje venceram" (BENJAMIN, 1987, p. 225), para retomar uma célebre expressão de Walter Benjamin.

Ao concluir o seu trabalho, Bethencourt afirma:

A relação entre historiografia e memória imperial é ainda mais complexa. A democratização da historiografia através do sistema de ensino desde a fase final da monarquia constitucional, passando pela República e pelo Estado Novo, alimentou a memória colectiva, contribuindo para a difusão de figuras míticas como a do infante D Henrique. A experiência de uma colonização tardia em África, concentrada afinal nos anos 60, aliada à presença maciça de sucessivas "fornadas" de soldados portugueses na guerra colonial entre 1961 e 1974, constituiu um elemento poderoso de renovação desta memória coletiva [...]. O vazamento dessa memória para a toponímia, nomeadamente de Lisboa [...] constitui elementos de reforço do quadro de referências da identidade nacional. Entre a perpetuação da memória e a construção da identidade, a historiografia manteve até aos nossos dias uma utilidade ambígua ao serviço de valores e regimes que não sofreu rupturas com a revolução de Abril, apenas adaptações a novas necessidades e novos projetos políticos. (BETHENCOURT, 2003, p. 80-81)

Tal historiografia, profundamente marcada ao longo dos séculos pela vocação atlântica e expansionista, oferece uma ótima perspetiva para pensar o "irrealismo prodigioso que os Portugueses se fazem de si mesmos" (LOURENÇO, 2010, p. 23).

O estudioso brasileiro Mário César Lugarinho, ao analisar a obra poética de Manuel Alegre, estendeu-se numa atenta reflexão sobre o contexto histórico e cultural no qual a experiência artística de Alegre se inscreve. Uma parte importante deste estudo, denominado Manuel Alegre: mito, memória e utopia, envolve a relação existente entre poesia e história, a fim de delinear as dinâmicas temporais e as interpretações do passado em Portugal. Esta ferramenta, importante para discutir acerca da produção artística de um autor que muito questionou e trabalhou temas e materiais provenientes da tradição lusitana, mostra-se útil para ler toda aquela literatura portuguesa contemporânea, marcada por um forte sentido de historicida- 
de. Para Lugarinho, uma caraterística da historiografia em Portugal, seria a presença de uma forte componente literária, que acaba por confundi-la com as memórias do passado:

Esta historiografia anterior amparava-se num futuro, sempre lugar da utopia, em que se daria a reversão do presente em outra perspectiva adversa. Isto é, o Quinto Império, o reino do Espírito Santo, etc, com o Portugal, certamente ao centro e à frente das nações [...]. Acresce-se a isto que a literatura foi compreendida, durante muito tempo, séculos, até, como fonte primária da História [...]

Tal procedimento configura uma formulação sui generis para a historiografia de uma nação - as alegorias literárias determinaram a narrativa da História. Poeta e ficcionista são alçados à condição de historiadores, cronistas, e arquivistas, servos dedicados à Memória. (LUGARINHO, 2004, p. 40)

Contrariamente ao que foi teorizado por Walter Benjamin (1978, pp. 222-235), em Portugal, as alegorias oferecidas pela arte e pela literatura, em vez de constituir a narração de uma outra história - a história dos vencidos -, delinearam as principais coordenadas de uma historiografia que engloba elementos do mito e que, por conseguinte, facilita a perpetuação dos traços proféticos que exatamente no mito se inserem. Daqui, a forte presença do elemento messiânico e da enunciação profética, que configura o destino português e que fazem do sebastianismo um elemento fulcral na construção da identidade portuguesa. Mitos, sonhos e profecias, além de serem recursos que alimentaram as literaturas desde os alvores, em Portugal, foram conotando e participaram na construção da história feita pelo poder durante os séculos.

A partir destas considerações, seria então possível perceber a necessidade, nos autores preocupados com questões identitárias, de desconstruir a memória do império e de oferecer-lhe outros sentidos. Desta forma, principalmente depois do 25 de abril 1974, várias obras ofereceram uma diferente visão dos acontecimentos, em linha com as memórias de quem sofreu o passado mais recente - em particular a experiência da Guerra Colonial, e as suas consequências. Tal movimento, sem deixar de refletir acerca da própria tradição literária, continua a contribuir para a construção de uma "poética da Nação", e para delinear uma identidade coletiva compartilhável:

Com isso, a Literatura Portuguesa, que tanto usufruiu desta mística buscando constituir uma temática permanente desde, pelo menos, Os Lusíadas até a Mensagem, irá pôr em causa sua própria constituição, buscando-se reconstruir por outros paradigmas, tão logo reconhece o momento da ruína, quando verifica que a promessa da utopia inscrita na tradição era, em verdade, instrumento do poder. (LUGARINHO, 2004, p. 50) 
Portanto, o que fica é uma literatura que, destruindo o imaginário utópico promovido pelo poder, se faz testemunho da perda, representando o resto, as ruínas do império. Em Excepção Atlântica: pensar a Literatura da Guerra Colonial, Roberto Vecchi define assim toda aquela produção literária produzida a partir de experiências traumáticas:

A literatura de uma experiência [...] envereda pelo rumo da ficcionalização, da verosimilhança da vivência como modo para testemunhar o que ainda não foi dito e que resiste a deixar-se dizer. O que corresponde a uma opção para salvá-la apesar do seu escoamento e da sua destruição. O que resta deste processo é, justamente, um resto, um resíduo que comunicará sempre problematicamente com a totalidade perdida. (VECCHI, 2010, p. 43)

Como sugere Roberto Vecchi, o resto está aqui entendido na dupla etimologia do termo, seja como perda, mas também como permanência $\nabla$ algo que fica, de forma estável, ao longo do tempo:

A primeira por remeter ao verbo grego leipo, que corresponde ao verbo latino linquo, de que deriva uma palavra residual como relíquia e marca a falta, a ausência, o abandono. A segunda vai no sentido oposto, derivando da palavra latina restus e indica estabilidade, firmeza e resistência" (VECCHI, 2010, p. 44).

Aquela literatura portuguesa contemporânea, que testemunha os acontecimentos trágicos do passado mais recente, seria então apenas fragmentos, restos e memórias de uma história cuja plenitude não é atingível. O que fica são, portanto, ruínas: tanto as do império, quanto as lembranças fragmentadas de quem passou pelo trauma e que, através da máquina literária, procura recompor, mesmo sendo essencialmente algo de parcial. Porque, como afirma Roberto Vecchi, "a ruína pode ser simultaneamente, de acordo com a reconstrução crítica, tanto perda do resto como presença do passado enquanto tal, ficando assim patente a multiplicidade semântica do conceito." (VECCHI, 2010, p. 44)

De facto, em Portugal, uma panorâmica daquela literatura que questiona a memória da Guerra Colonial e das suas consequências, mostraria restos, ruínas, fragmentos de memórias coletivas e pessoais, nos quais, através do trabalho crítico, seria possível vislumbrar a narração da perda de identidade e, ao mesmo tempo, da tentativa de traçar as coordenadas para reconfigurá-la, libertada dos fantasmas imperiais.

É nesta perspetiva que proponho aqui uma leitura de O Retorno, de Dulce Maria Cardoso: a partir das ruínas - consideradas como restos, na dupla etimologia, do império e da própria experiência -, tentar delinear uma narração que participa na construção de uma identidade, que tenha em conta as dinâmicas ausentes numa historiografia sempre ideologicamente ao serviço do poder. 


\section{O RETORNO: DESCONSTRUÇÃO E TESTEMUNHO}

O romance de Dulce Maria Cardoso foi publicado no 2011 e, através da voz de Rui, adolescente de quinze anos, representa uma antiepopéia: o conto realístico da perda, do momento em que, sem mais sonhos imperiais, Portugal tem que aceitar, no espaço físico da cidade de Lisboa, os restos concretos do fim do Ultramar.

O tempo dos acontecimentos narrados é o período controverso e tumultuoso que envolveu o país depois da Revolução dos Cravos. Está-se entre os meses que precederam à proclamação de independência de Angola e os meses apenas seguintes, assinalados por referências temporais contínuas durante as páginas do romance. Assim, através de tais referências, $o$ leitor pode colocar a pequena história pessoal da família de retornados, a qual Rui pertence, dentro da historiografia oficial: a ponte aérea de Angola (Luanda e Huambo - na altura chamada Nova Lisboa) para Lisboa significa os meses de setembro e outubro do 1974 e a independência de Angola - momento central no romance - o dia 11 de novembro 1975.

Também o espaço em que se desenvolvem os acontecimentos é sempre real e bem definido: Luanda, cidade onde Rui nasceu e cresceu, lugar da despreocupação infantil - mas também do racismo colonialista e da convivência cheia de tensões entre africanos e portugueses (ou lusodescendentes); Lisboa, a cidade da chegada em Portugal, onde a realidade vista e vivida desmorona o imaginário propagandeado, nas colónias, pelo Estado Novo; e Estoril, que de facto é, no romance, o hotel onde foram temporariamente alojados os retornados.

A definição cuidada do espaço e do tempo da ação, que tem justamente referências historiográficas concretas, oferece à obra uma apetência realista. Todavia, o ponto de vista, magistralmente construído por Dulce Maria Cardoso, fica sempre ligado à figura do adolescente Rui, que interpreta a realidade através dos filtros provenientes dos seus quinze anos. A perda de raízes - e do pai, ausente em toda a parte central do romance - assim como os sonhos infantis e a sobrevivência numa realidade hostil são, efetivamente, fatores que interferem na visão que o narrador tem das coisas. Desta forma o que fica em $O$ retorno, é uma cuidada representação da realidade, que não visa uma reprodução "cientifica" desta, mas a construção mental que Rui faz, num movimento funcional à representação das hierarquias interpretativas e dos preconceitos subjacentes, tanto na última fase do colonialismo português, quanto no Portugal após 25 de Abril.

A partir da condição de um adolescente que, no caos geral que o rodeia, tenta cuidar da própria família - que, na ausência do pai, é constituída pela mãe, Glória, com doenças mentais e pela irmã um ano mais velha, Maria de Lurdes, também chamada Milucha - e assim se tornar um homem, Dulce Maria Cardoso consegue transmitir ao leitor a condição de fragilidade e perda, caraterística da nossa época: "nossa época, com a guerra moderna, o imperialismo e as ambições quase teológicas dos gover- 
nantes totalitários, é, com efeito, a era do refugiado, da pessoa deslocada, da imigração de massa" (SAID, 2003, p. 47).

Tendo em conta a posição fulcral que Rui desenvolve ao longo das páginas, seria possível considerar a obra como sendo um bildungsroman. A passagem da infância para a idade adulta do protagonista, num plano de fundo caraterizado pelo contexto violento - seja em termos de violência física seja mental - aparece justamente como elemento central. É através da formação de Rui, também no que diz respeito à sexualidade, elemento tópico nos romances de formação, que a autora atua o showing dos paradigmas sobre os quais se baseava o senso comune $e^{3}$ da altura, profundamente marcado pela aversão perante qualquer forma de alteridade, como os casos simbólicos dos negros e da homossexualidade - representada no romance pelo tio de Rui, Zé.

Apenas como exemplo, acerca dos africanos, lê-se: "aí é o preto, o preto é preguiçoso, gostam de estar ao sol como os lagartos, o preto é arrogante [...] o preto é burro não entendem o que se lhes diz, o preto é abusador [...], podia-se estar horas a falar do preto mas os brancos não gostavam de perder tempo com isso, bastava dizer, é preto." (CARDOSO, 2011, p. 25)

De facto, o narrador adolescente engloba e fica influenciado por tudo aquilo que vem de fora, como as conversas do pai, dos professores e do cabeleiro, entre outros, sem ter ainda uma consciência crítica - que lentamente irá aparecer durante a narrativa, mesmo sem ser completamente dominada por Rui, na medida em que se cumpre a formação do rapaz. Isto permite à autora manter, em toda a obra, uma focalização múltipla. Nos pensamentos do protagonista são de facto representados os vários pontos de vista através dos quais a realidade da altura era lida e, em certa forma, sustentada. Assim, é através das palavras do pai que Rui interpreta a falta de organização, caraterística dos contextos pós-conflito, que envolveu as tropas portuguesas que ficaram em Angola depois do 25 de abril:

Os soldados portugueses já quase não passam por aqui e os poucos que vemos têm cabelos compridos e as fardas desleixadas, os botões das camisas desapertados e os atacadores das botas por atar. Derrapam os jipes nas curvas e bebem Cucas como se estivessem de férias. Para o pai os soldados portugueses são uns traidores mas para o tio Zé são heróis antifascistas e anticolonialistas. (CARDOSO, 2011, p. 11-12)

No que diz respeito à rutura com os modelos coloniais e salazaristas, as palavras do professor da escola são testemunhos das mudanças no imaginário coletivo que ocorreram na altura, assim como da vontade de excluir obras consideradas como sendo ligadas à ideologia imperial. E, como era imaginável, a crítica envolve também Os Lusíadas:

O professor de português era novo usava o cabelo comprido e cheirava a liamba, levava a viola para as aulas e punha-se a cantar o Monangambé de forma tão sentida como se fosse um preto, $[. .$.$] não cantava bem mas era melhor ouvi-lo de-$ 
safinar Monangambé ou Mon'etu ua Kassule akutumissa ku San Tomé do que estar a estudar os cantos dos Lusíadas. O professor da turma $\mathrm{B}$ queimou Os Lusíadas, o império não devia ter existido e Os Lusíadas que o aclamam também não. (CARDOSO, 2011, p. 46)

$\mathrm{Na}$ mesma forma, também as considerações dos retornados sobre a revolução, a democracia e, mais em geral, as mudanças radicais que envolveram a vida de todos - portugueses e africanos, tanto em Portugal quanto nos países africanos - são significativas para refletir acerca da confusão que se seguiu à queda do Estado Novo.

Sempre através do seu olhar de adolescente atento às circunstâncias que o rodeiam, para tentar sobreviver a elas, Rui oferece, efetivamente, uma reportagem cuidada das lógicas e das dinâmicas mentais da época, representadas também a partir da posição de personagens simbólicas, como o Pacaça e João Comunista. Acerca de Pacaça lê-se: “o Pacaça é o porta-voz dos retornados e é o retornado mais retornado do hotel, nasceu em Angola, mas vivia em Moçambique e por isso odeia em igual medida o Rosa Coutinho que deu Angola aos pretos e Almeida Santos que fez o mesmo em Moçambique" (CARDOSO, 2011, p. 99).

Ou ainda: "nunca se esquece de dizer que tanto é retornado de Angola como de Moçambique, ou melhor, não sou retornado de coisa nenhuma que a bem dizer nunca aqui tinha posto os pés e já meu avô tinha saído daqui com a jura de nunca mais cá voltar" (CARDOSO, 2011, p. 116).

No que diz respeito a João Comunista, o registo mantém o tom veladamente irónico, como no caso de Pacaça:

O João Comunista tem uma camisa às flores e o cabelo pelas costas que atira para trás com gestos bruscos para não parecer uma mulher a ajeitar-se. Acho que um comunista a sério não usa uma camisa às flores mas o João Comunista não é comunista, chamam-lhe assim por estar sempre a dizer que o império era uma vergonha, que devíamos ter vergonha por termos subjugado inocentes durante tantos séculos. (CARDOSO, 2011, p. 116)

Em $O$ retorno, através da voz do adolescente, a narração inclui e representa portanto também as posições e as opiniões das personagens que pertencem às "alteridades". Todavia, na medida em que vão mudando as posições físicas e sociais do protagonista, variam também as alteridades: se no primeiro capítulo Rui e a sua família se encontram na posição de ex-colonizadores e então daqueles que tiveram a hegemonia, na parte seguinte serão eles mesmos os subalternos. Romance da perda, $O$ retorno é também uma obra que tenta representar "o perigoso território do não-pertencer, para o qual, em tempos primitivos, as pessoas eram banidas e onde, na era moderna, imensos agregados de humanidade permanecem como refugiados e pessoas deslocadas" (SAID, 2003, p. 50). 
Por conseguinte, se na primeira parte a diversidade residia nos africanos, na segunda parte, através de uma subversão completa das perspetivas, os "outros" tornaram-se, justamente, os portugueses. De qualquer forma, a relação entre as alteridades nunca está apresentada de maneira pacífica: "O soldado não baixa a arma, um branco é um escravagista, um colonialista, um imperialista, um explorador, um violador um carrasco, um gatuno. Qualquer branco é isso tudo ao mesmo tempo, e não pode deixar de ser odiado" (CARDOSO, 2011, p. 48).

Igualmente, também em Portugal, as dinâmicas que regulam as relações com os retornados continuam a basear-se em preconceitos:

Os empregados não nos querem cá e não gostam de nos servir. Acreditam que os pretos nos puseram de lá para fora porque os exploramos, perdemos tudo mas a culpa foi nossa e não merecemos estar aqui num hotel de cinco estrelas a sermos servidos como o éramos lá. (CARDOSO, 2011, p. 91-92)

No entanto, se, no plano individual, o lento caminho para a formação tumultuosa do protagonista permitiria considerar $O$ retorno como sendo um bildungsroman, no plano da experiência coletiva, a encenação da perda e a tentativa de questionar algo de atual na sociedade portuguesa contemporânea, partindo de um momento fulcral da história mais recente - como a Guerra Colonial e o drama dos retornados -, tornaria possível considerar $O$ retorno como sendo um romance histórico. Refletindo acerca do romance histórico na pós-modernidade, Maria da Fátima Marinho sublinha como nele o passado seria considerado como algo que "não está terminado, mas que se constrói em cada acto de escrita [...], numa tentativa de desconstrução" (MARINHO, 1999, p. 37). Tal consideração do passado é também a que sustenta, de facto, o romance de Cardoso, embora este não tenha, supostamente, o distanciamento temporal necessário para falar de romance histórico - a crítica concorda em considerar entre quarenta e sessenta anos o distanciamento mínimo suficiente (FLEISHMAN, 1971).

Acerca disso, Marinho evidencia um fator muito importante nas reflexões sobre o romance histórico:

casos há em que estudiosos ignoram esta limitação temporal, considerando que factores históricos determinantes, como uma revolução ou uma guerra, mesmo próximos ou directamente vivenciados pelo autor empírico, podem, se aproveitados num universo romanesco, ser apelidados de histórico (MARINHO, 1999, p. 14).

Tal consideração tornaria legítima a inclusão da obra de Dulce Maria Cardoso no género em questão. O que acontece no texto pode de facto ser lido também através das análises de György Lukás, sobre a obra de Walter Scott, considerado o iniciador do género. Para o crítico húngaro, na representação da psicologia, das mentalidades e dos hábitos de uma certa época, residiria a marca fundamental daquilo que é possível chamar ro- 
mance histórico. A história não seria apenas uma moldura, mas o contexto exterior e interior às personagens (LUKÁS, 1963). Na pluralidade de perspetivas que sustenta $O$ retorno encontrar-se-ia uma marca importante do subgénero denominado "romance histórico": Cardoso, nas próprias encenações do passado, trabalha para tentar representar, com o maior cuidado possível, a psicologia do tempo narrado, mostrando as falhas e a precariedade dos paradigmas que sustentaram a colonização portuguesa na África, os anos da guerra, e os que lhes seguiram.

Aquilo que acontece em $O$ retorno pode então ser lido à luz das reflexões desenvolvidas por Marinho em O romance histórico em Portugal, em particular no que diz respeito ao romance histórico pós-moderno, em que a representação da história assume um valor político:

O romance histórico pós-moderno torna-se, assim, não uma forma de conhecimento histórico (como os românticos pretendiam), mas a inquirição da possibilidade de utilizar esse mesmo conhecimento de uma perspectiva epistemológica ou política. Tal constatação leva à tomada de consciência do caráter eminentemente crítico e contextualizado de qualquer forma de conhecimento histórico na actualidade, facto que se traduz frequentemente pelo uso da ironia. (MARINHO, 1999, p. 39)

No romance, o acontecimento histórico que desencadeia as ações é certamente a Guerra Colonial. Todavia, em O retorno o conflito bélico não aparece: as mudanças radicais que envolveram tanto a política quanto a vida social e o imaginário, representadas no romance já a partir do primeiro capítulo $\nabla$ através das imagens das tropas descontroladas, do professor que queima Os Lusíadas e dos preparativos para a emigração - são consequências diretas do fim da guerra. Em New and old war: organized violence in a global era, Mary Kaldor sublinha como a emigração em massa seria uma consequência das políticas que regram os conflitos da contemporaneidade (KALDOR, 1999) - consideração compartilhada também por Edward Said em Reflexões sobre o exílio. Assim, o primeiro capítulo de $O$ retorno representaria exatamente o cenário caraterístico do momento pós-conflito: atmosfera militarizada, tropas de diferentes fações a exigir autoridade, vinganças, perseguições e uma enorme quantidade de seres humanos a emigrar:

A minha irmã acusa o pai de não se importar com o que nos possa acontecer e por vontade da mãe teríamos ido embora há muito tempo, ainda antes do Sr. Manuel. Não acredito que o pai não se importe connosco apesar de não perceber por que ainda não fomos embora quando pode acontecer-nos uma coisa má em qualquer momento. (CARDOSO, 2011, p. 11)

Concluída a secular experiência colonial portuguesa, O retorno pode ser considerado como tudo aquilo que ficou - isto é: as ruínas $\nabla$ quando a arquitetura mítica que sustentava o imaginário coletivo portu- 
guês desmoronou. Já não existe nenhum destino mítico. O que fica são apenas os restos protagonistas de O retorno: centenas de contentores abandonados nos cais de Lisboa, provenientes das ex-colónias, e mais de meio milhão de pessoas desalojadas.

De facto, uma vez desconstruída a memória mítica propagandeada pelo fascismo, torna-se evidente a realidade do colonialismo português, escondida atrás da magníloqua retórica oficial. Em "Entre Próspero e Caliban: colonialismo, pós-colonialismo e inter-identidade", Boaventura de Sousa Santos afirma:

Nos estudos pós-coloniais, o colonizador surge sempre como um sujeito soberano, a encarnação metafórica do império. Ora, no colonialismo português tal não pode pressupor-se sem mais. Só durante um curto período [...] é que o colonizador incarna o império, e mesmo assim só em circunstâncias muito selectivas. Fora disso, o colonizador apenas se representa a si próprio. É um auto-império [...]. Mas precisamente porque esta identidade imperial não lhe é outorgada por ninguém para além dele, ele é de facto um sujeito tão desprovido de soberania quanto o colonizador. (SANTOS, 2006, p. 229)

Na base desta ideia residiria o facto de ser Portugal não um país hegemónico nas relações globais, mas dependente dos "países centrais". Isto significa que as dinâmicas que sustentaram a construção da identidade, pertencem ao mesmo tempo às do colonizador e às do colonizado, criando então uma cultura de fronteira e um colonialismo fora da norma - constituída, nas teorias de Boaventura de Sousa Santos, pelo modelo britânico.

A identidade do colonizador português é, assim, duplamente dupla. É construída pela conjunção de dois outros: o outro que é colonizado e o outro que é o próprio colonizador enquanto colonizado. Foi esta duplicidade de alta intensidade que permitiu ao português ser, muitas vezes, tratado mais como emigrante, do que como colono, nas «suas» próprias colónias. (SANTOS, 2006, p. 228)

É exatamente esta realidade de emigrantes e de dupla alteridade que fica, uma vez que a experiência colonial em África perdeu a própria aura mítica. E é desta forma que em $O$ retorno é apresentada uma parte dos colonos - os que não tiveram relações com o poder: "o pai sabia o que dizia, tinha ido para África para fintar a pobreza, em África fintava-se tudo, a morte, a pobreza o frio e até a maldade [...]" (CARDOSO, 2011 p. 84).

Tal subversão de perspetivas devida ao falhar do imaginário mítico perante a realidade das coisas manifesta-se, no romance, também na maneira de representar alguns temas recorrentes na literatura portuguesa. O principal é sem dúvida a viagem, elemento tópico desde as crónicas e os relatos de viagem. 
No romance de Dulce Maria Cardoso, a viagem é, na verdade, o momento fulcral do texto, e é daí que vem o título da obra: O retorno é justamente a viagem de regresso dos portugueses à velha metrópole do império - uma viagem inversa, em relação às decantadas pela tradição literária portuguesa. Efetivamente, em $O$ retorno não há espaço para o imaginário mítico imperial. Também as viagens que conduziram os pais de Rui a Angola - as viagens da metrópole para as terras de Ultramar $\nabla$ são referidas através das lembranças do rapaz, sem nenhuma aura épica. Não há versos de Camões para contar a chegada nas colónias, mas sim a realidade dos emigrantes, de precariedade e pobreza, denunciada nas análises de Boaventura de Sousa Santos. No romance lê-se:

Quando vim ter com o vosso pai trouxe a mala amarela cheia de enxoval todo feito por mim, trabalhava no campo durante o dia e bordava aos serões, a pressa que tinha em vir para cá nem me deixava ter sono, não queria acreditar que ia ter uma casa com torneiras, parecia impossível, por causa das pressas tive de desfazer esta dália três vezes, ainda se nota aqui o tecido maltratado, uma casa com torneiras queria dizer que nunca mais teria que acartar a água da fonte [...], uma casa com torneiras de onde saísse a água sempre que se queria só era possível muito longe daquela miséria, num sítio tão longe que nem o frio lá chegava [...]. (CARDOSO, 2011, p. 19)

Por outro lado, o próprio movimento de Luanda para Lisboa, fulcral no romance, representa o momento em que a realidade imaginada deixa definitivamente espaço à concreta. Em O retorno, a desconstrução dos falsos paradigmas erigidos pelo fascismo é um processo natural perante os olhos de Rui, menino nascido e criado na Angola colonial, onde a imagem da mãe-pátria era filtrada pelo imaginário coletivo, propositadamente construído pelo poder, também através duma historiografia sempre influenciada pela ideologia dominante:

A metrópole tem de ser como este hotel que até no elevador tem uma banqueta forrada a veludo. Portugal não é um país pequeno, era o que estava escrito no mapa da escola, Portugal não é um país pequeno, é um império do Minho a Timor. A metrópole não pode ser como hoje a vimos no caminho que o táxi fez, ninguém nos ia obrigar hinos aos sábados de manhã se a metrópole fosse tão acanhada e suja, com ruas tão estreitas onde parece que nem cabemos.[...]

Não, a metrópole não pode ser como hoje a vimos. A prova de que Portugal não é um país pequeno está no mapa que mostrava quanto o império apanhava a Europa, um império tão grande como daqui até à Rússia não pode ter uma metrópole com ruas onde mal cabe um carro, não pode ter pessoas tristes e feias nem velhos desdentados nas janelas tão sem serventia que nem para a morte têm interesse. (CARDOSO, 2011, p. 83-84) 
Assim, para Rui, a chegada em Portugal tem um tom completamente antiépico. Não há poemas para descrever o momento, apenas o velho mapa da escola, que mostrava o império português, a aparecer como puído e desgastado: "foi esquisito pisar na metrópole, era como se estivéssemos a entrar no mapa que estava pendurado na sala de aula. Havia sítios onde o mapa estava rasgado e via-se um tecido escuro ou sujo por trás [...]." (CARDOSO, 2011, p. 76-77)

Se a viagem, em $O$ retorno, tem uma conotação e um sentido antagónico, em relação à tradição literária portuguesa, também a representação de África, lugar de partida, manifesta profundas discrepâncias com as que a literatura pós 25 de Abril ofereceu à memória coletiva. Em "Uma intensa disseminação: a África como locus na literatura portuguesa”, Inocência Mata analisa as configurações através das quais a África foi representada na literatura portuguesa. Se na literatura colonial a África aparece como lugar hostil, tendo como finalidade ideológica desenhar "a apologia do império e da colonização" (MATA, 2011, p. 133), depois da Guerra Colonial e das independências, a literatura fez da África o locus do uncanny, da perturbação individual, tentando procurar uma catarse coletiva. Escreve Inocência Mata:

Depois das independências, a África evocada era-o primeiramente enquanto localização da inquietação colonial e imperial, mais precisamente por ser lugar de um tempus horribilis histórico - a Guerra Colonial - e já não propriamente locus horrendus, como fora na construção da ultramarinidade e da colonialidade, em que o confronto era com o espaço humano e natural (MATA, 2011, p. 133)

Na medida em que floresceram as obras literárias centradas sobre a Guerra Colonial, também a África foi adquirindo significações peculiares, estranhas às dinâmicas da literatura colonial. Sempre no já mencionado ensaio, Inocência Mata oferece uma panorâmica dos sentidos que este lugar do Ultramar conserva nas obras mais recentes:

Outras são, já se viu, agora, as significações deste locus de além-mar: vão desde o exemplum da inadequação e do descalabro da empresa colonizadora (como em As Naus) ao lugar de conhecimento do "eu" (Niassa), do mundo globalizado (Lenin Oil) e de compreensão de um passado recente, grupal e segmental (Cisne de África), e ao locus iniciático e catártico de reconstrução identitária, tanto ao nível individual (Caderno de Memórias Coloniais) quanto ao nível coletivo (Lourenço Marques). (MATA, 2011, p. 138)

Que seja exemplum, ou lugar de reconstituição identitária, ou de reconhecimento do "eu", a experiência da realidade africana empurra o sujeito para uma reconsideração das próprias hierarquias interpretativas. No plano individual, isto interfere na relação do sujeito com o próprio "eu", enquanto, no plano coletivo, traz uma reconfiguração das coordenadas identitárias. 
Em $O$ retorno, como para as viagens, a África tem conotações diferentes em relação às obras analisadas por Inocência Mata. De facto, as perspetivas sofreram uma subversão radical: é Portugal a ter, perante os olhos de Rui, o papel de perturbador, enquanto a África é o lugar da infância e da prosperidade.

Lisboa, por conseguinte, está apresentada como contemporaneamente locus horrendus $\nabla$ constituído por uma realidade completamente dissemelhante à propagandeada, mas que conserva a pobreza e as faltas das lembranças dos pais - e tempus horribilis: o tempo da precariedade, da falta de raízes, da marginalização e da discriminação sempre presente, nas instituições como na vida social:

A puta de matemática pôs os retornados na fila mais afastada das janelas, nos lugares com menos luz [...]. Um dos retornados que responda, a puta nunca diz os nossos nomes, um dos retornados que responda, era o que faltava, nunca abro a boca, o retornado da carteira do fundo que responda, insistiu a gaja, estava mesmo a querer farra. Custa assim tanto decorar o meu nome, se me chamasse Kijibanganga ainda tinha desculpas mas Rui, porra, é um nome fácil e mesmo que me chamasse Kijibanganga a puta tinha obrigação de decorar. [...] (CARDOSO, 2011, p. 141)

E ainda: "Estar na metrópole ainda é pior para as raparigas, os rapazes de cá dizem que as retornadas lá andavam com os pretos. E as raparigas de cá não querem ser amigas das retornadas para não serem faladas, as retornadas têm má fama, usam saia curta e fumam nos cafés." (CARDOSO, 2011, p.143)

A África, pelo contrário, representa as raízes, a infância e a família. Para Rui, Angola é casa, ou seja, tudo aquilo que o quarto de um hotel de cinco estrelas em Estoril nunca poderá oferecer. É o espaço físico do "eu", da identidade pessoal, o lugar do pertencer: "O pai nunca fala da metrópole, a mãe tem duas terras mas o pai não. Um homem pertence ao sítio que lhe dá de comer, a não ser que tenha um coração ingrato". (CARDOSO, 2011, p. 11)

Por conseguinte, a imagem de Angola no romance - é bem lembrar que se trata aqui da Angola "branca", a vivenciada pelos colonizadores, sem referência nenhuma à realidade dos africanos $\nabla$ é a da prosperidade, sempre mencionada durante as páginas do romance, uma terra "tão farta onde nunca poderá haver fome” (CARDOSO, 2011, p. 96). Assim, Luanda aparece nas recordações de Rui como um lugar de sossego, cuja força tranquilizadora aparece também nos sonhos:

A noite passada sonhei que estava no Mussulo e que de repente o céu tinha ficado carregado de pássaros, gaivotas, andorinhas do mar, corvos marinhos, o céu estava tão cheio de pássaros que não havia ar. E no entanto apesar daquela aflição, eu estava contente porque pensava pelo menos estou no Mussulo. Fiquei a repetir, pelo menos estou no Mussulo [...]. (CARDOSO, 2011, p. 136) 
Portugal e Angola, em O retorno, apresentam, de facto, traços completamente diferentes e às vezes antagónicos. Tal pluralidade de perspetivas, consequência de vivenciais individuais peculiares, estimula a reflexão sobre as possibilidades de a experiência da dor e da violência, participarem da elaboração da identidade coletiva. As ruínas do império são, em O retorno, os restos das experiências que o autor empírico viveu, representados ora através das estratégias narrativas do bildungsroman ora através do potencial político do romance histórico pós-moderno.

Desta maneira, a encenação da viagem, a violência física e mental e a representação dos lugares onde as contradições interiores ao discurso oficial - que, como referi, se nutriu das alegorias da literatura - explodiram, são, com efeito, rastos para a construção de uma poética da nação que ultrapasse os paradigmas ligados ao imaginário mítico. Já não um contradiscurso, mas simplesmente um discurso alternativo que se baseia nas perspetivas das vítimas dos processos políticos e sociais que envolveram Portugal durante os últimos cinquenta anos. Assim, a literatura produzida a partir da viragem pós 25 de Abril apropria-se da faculdade de construir um outro discurso, que parta daquelas realidades incómodas e que nunca apareceram na historiografia, sempre ideologicamente orientada pelas dinâmicas do poder.

\section{REFERÊNCIAS BIBLIOGRÁFICAS}

ANDERSON, Benedict. Imagined communities: reflections on the origin and spread of nationalism. London: Verso 1991.

BETHENCOURT, Francisco. Desconstrução da memória imperial: literatura, arte e historiografia. In: RIBEIRO, Margarida Calafate, FERREIRA, Ana Paula (orgs.). Fantasmas e fantasias imperiais no imaginário português contemporâneo. Porto: Edição Campo das Letras, 2003, pp. 69-81.

CARDOSO, Dulce Maria. O retorno. Lisboa: Tinta-da-china, 2011.

COELHO, Jacinto do Prado. Originalidade da literatura portuguesa. Lisboa: ICLP, 1992.

FLEISHMAN, Avrom. The english historical novel: Walter Scott to Virginia Woolf. Baltimore/London: Johns Hopkins University Press, 1971.

GRAMSCI, Antonio. Quaderni del carcere. Torino: Einaudi, 1975.

KALDOR, Mary. New and Old Wars. Organized Violence in a Global Era. Standford: Standford University Press, 1999.

LOURENÇO, Eduardo. O imaginário português neste fim de século. JL-Jornal de Letras, Arte \& Ideias. Ano XX, pp. 20-26, 29 dez. 1999.

LUGARINHO, Mário César. Manuel Alegre - mito, memória, utopia. Lisboa: Edições Colibri, 2004. 
LUKÁS, György. Il romanzo storico. Torino: Einaudi, 1977.

MARINHO, Maria de Fátima. O romance histórico em Portugal. Porto: Ed. Campo das Letras, 1999.

MATA, Inocência. Uma intensa disseminação. A África como locus na literatura portuguesa. Letras com Vida - Literatura, Cultura, Arte. Lisboa: Gradiva, CLEPUL, n. 3, p. 132-140, set. 2011.

SAID, Edward - Reflexões sobre o exílio e outros ensaios. Trad. Pedro Maia Soares. São Paulo: Companhia das Letras, 2003.

SANTOS, Boaventura de Sousa. Entre Próspero e Caliban: colonialismo, pós-colonialismo e inter-identidade. In: A gramática do tempo: Para uma nova cultura política. Porto: Edições Afrontamento, 2006, p. 211-254.

VECCHI, Robero. Excepção atlântica: pensar a literatura da Guerra Colonial. Porto: Edições Afrontamento, 2010.

Recebido para publicação em 31/10/2017

Aprovado em 05/03/2018

\section{NOTAS}

1 Doutorando em Literatura, Cultura e Contemporaneidade na Pontifícia Universidade Católica do Rio de Janeiro (PUC-Rio), formou-se em Lettere Moderne na Università di Siena (Itália). Tem Mestrado em Estudos Comparatistas $\bigotimes$ Faculdade de Letras, Universidade de Lisboa.

2 Em Imagined communities: reflections on the origin and spread of nationalism, Benedict Anderson salienta o facto de ser, a construção de um imaginário coletivo baseado sobre uma representação mítica, e não bem histórica, do passado, uma caraterística comum dos nacionalismos europeus durante a modernidade. (ANDERSON, 1991) A exceção portuguesa, marcada por uma longa - e talvez só parcialmente alcançada - modernidade, prolonga de facto tais estratégias até os meados dos anos setenta, enquanto em outros contextos - como o italiano e o alemão, entre outros - o fim da Segunda Guerra Mundial significou uma profunda rutura com estas dinâmicas.

3 Com senso comune (sentido comum) refiro-me à expressão discutida por Antonio Gramsci (GRAMSCI, 1975). 